\title{
Technical Communication and Project Management: A Mixed Methods Study in a Corporate Context
}

\author{
Rosemarie T. Miller \\ Indiana University-Purdue University \\ Indianapolis \\ millerrt@iupui.edu
}

\author{
Marjorie Rush Hovde \\ Indiana University-Purdue University \\ Indianapolis \\ mhovde@iupui.edu
}

\begin{abstract}
A mid-size manufacturing business grew from a family start-up to a global leader in less than three decades, but no plan was developed for Project Management or Technical Communication. Recently upper management acknowledged this corporate weakness and asked us to research interdepartmental communication, with emphasis on New Product Development. Formal Project Management had not previously been attempted at this company, and New Product Development was conducted as a committee. After a literature review, we conducted a mixed-method study to assess employee satisfaction with current project processes, technology, and communication. A survey combining two existing tools was administered to all personnel in departments involved with New Product Development. Downs and Hazen's Communication Satisfaction Questionnaire was tailored to evaluate the company's communications, and a customized version of the Universal Technology Adoption and Use Theory tool assessed technology use and acceptance within the company. Subsequent to the survey, all department managers directly involved with New Product Development at the organization were interviewed. Quantitative results were analyzed statistically, and qualitative results were analyzed through open coding. Findings from this study can provide insight into the dynamics of improving both Project Management and Technical Communication within a corporate context.
\end{abstract}

Index Terms - Communication satisfaction, corporate communication, new product development, project management, technology use and acceptance.

\section{INTRODUCTION}

Technical and Professional Communication (TPC) and Project Management (PM) have multiple overlapping areas of concern in workplace practice [1], but few empirical studies have been conducted that provide a finegrained view of the dynamics of these interactions within today's workplaces.

Effective TPC has been repeatedly cited as perhaps the most important success factor within an organization ([2], [3], especially in terms of PM and new product development (NPD) [4]-[10].

TPC is not merely a data transfer system, but also a social process [9], so project managers must understand the social environment of stakeholders in order to communicate efficiently and effectively. Communication methods that work well within a project team may not be acceptable to outside stakeholders, predisposing communications to break down [10].

When planning a communication strategy, project managers must take into account social influences internal to an organization's culture for communication and its technology, which is often not fully used by employees. Lack of user acceptance, measured by the user's perceived ease of use and usefulness of the technology, has long been a barrier to the success of information systems [11]. Attitudes toward technology have been measured by IT using the Technology Acceptance Model (TAM), developed in 1986 by Davis and Begozzie which is still in use today [12]. Accepting new technology also involves social factors, as indicated in the Universal Technology Adoption and Use Theory (UTAUT), introduced by V. Venkatesh, M.G. Morris, G.B. Davis, and F.D. Davis in 2003 [13].

New projects are the core of industry growth; "Projects create value in the form of improved business processes, are indispensable in the development of new products and services, and make it easier for companies to respond to changes in the environment, competition, and the marketplace" [14, p.17]. Effective PM and TPC are crucial to organizations but are often not practiced well.

The Project Management Institute (PMI) and its publication A Guide to the Project Management Body of Knowledge (PMBOK ${ }^{\circledR}$ guide) (PMBOK), world leaders

This is the author's manuscript of the article published in final edited form as: 
[15] in project management standards since the late 1980's,outlines management standards for planning, managing, and controlling communication within a project. PMBOK can be used in conjunction with other management techniques, such as Six Sigma, Lean, Agile, or various Gateway processes.

PM and NPD are similar, yet have distinct differences. PMBOK states, "A project is a temporary endeavor undertaken to create a unique product, service, or result" $[14$, p. 3]. NPD is a process of steps that need to be taken for each new product. The process structure of "gateways" or "stages" can be reused for many unique new products. For both PM and NPD, each organization must tailor the flow to its own needs. Principles of communication in PM and NPD are similar [5], and this paper will consider them together.

Communication and technology are deeply interwoven in organizations today. Reports, email, minutes, presentations, and such are all done electronically, with less reliance on paper communications than ever before, so we included the use of communication technology in TPC within NPD processes.

This study investigated the possible causes of poor interdepartmental communication at one organization to make recommendations based on the study results and current literature. Employees involved with NPD completed a questionnaire, and follow-up interviews with department managers were conducted.

The study uncovered four primary areas of concern when examining interdepartmental communications during NPD: lack of central authority, confusion of department roles, the structure of project meetings, and basic communication.

\section{Methodolgy}

\section{Introduction}

Based on the issues raised in current literature, central research questions for this study included:

- How effective are current NPD practices within this organization, especially those related to TPC? What are the central concerns that need to be addressed to enhance NPD?

- How satisfied are employees with the communication technology available to them that might affect NPD?

Understanding the communication level of the stakeholders within PM or NPD is vital for a manager to determine which communication tools will most likely to achieve the best results. In this organization, all vital communications within this organization are done with technology:

- $\quad$ reports come from Syteline, (an enterprise resource planner system,)

- $\quad$ projects are requested and monitored in Task Manager (an in-house program),
- $\quad$ engineering changes notices $(\mathrm{ECN})$ are reported through the Global Document System (GDS) (also an in-house program), and

- facility monitors linked to the internal intranet.

Because communication satisfaction and technology acceptance are fundamental to the communication strategy of PM and NPD, these topics were addressed together. We narrowed them down to the needs of the project managers and department managers within this organization.

As a measurement of organizational overall communication satisfaction, Downs and Hazen's Communication Satisfaction Questionnaire (CSQ) has been a major data tool since 1977, and re-validated as an audit tool by Zwijze-Koning and De Jong in 2007 [16]. Portions of the CSQ concerning areas pertinent to this organization were used in the survey of this organization employees and managers.

This research gathered both quantitative and qualitative data. The questionnaire sections pertaining to CSQ and UTAUT in relation to the organization's technical communication for PM and NPD provided quantitative data, while personal interviews with department/project managers provided qualitative data.

\section{Organizational context}

NPD at this mid-sized manufacturing company involves collaboration among many departments, yet the needs of the various departments have not always been communicated in a clear and timely manner. This miscommunication has cost the company excessive time for NPD and often resulted in hastily-produced products that have continuously changed as they were being built.

In this organization, NPD has traditionally faced delays and setbacks due to unavailable parts, mid-design changes, confusion of department roles, or forgotten notifications. The various departments do not fully understand their duties or the duties of their teammates. Departments do not receive updates or work orders in a timely manner. Decisions are made without involving departments that are affected due to the failure to understand what information is essential to other departments.

Poor TPC during NPD may be caused by varying education levels, insufficient/incomplete information, having the wrong communication tools, using a wrong process, language differences, and/or inadequate company resources.

\section{Participants}

The survey (see appendix A and section VI below) was sent to all members of the departments directly involved in NPD. A total of 86 invitations were sent to the following departments: 
TABLE 1. PARTICIPANTS.

\begin{tabular}{|l|c|c|c|}
\hline Department & Sent & Responses & $\begin{array}{c}\text { Percent } \\
\text { participation }\end{array}$ \\
\hline Marketing & 13 & 7 & $53.8 \%$ \\
\hline $\begin{array}{l}\text { Information } \\
\text { Technology }\end{array}$ & 8 & 2 & $25.0 \%$ \\
\hline $\begin{array}{l}\text { Material Control } \\
\text { (Purchasing) }\end{array}$ & 7 & 5 & $71.4 \%$ \\
\hline Corporate Sales & 22 & 4 & $18.2 \%$ \\
\hline $\begin{array}{l}\text { Customer } \\
\text { Service }\end{array}$ & 19 & 8 & $42.1 \%$ \\
\hline $\begin{array}{l}\text { Product } \\
\text { Development } \\
\text { (Engineering) }\end{array}$ & 17 & 12 & $70.1 \%$ \\
\hline Total & $\mathbf{8 6}$ & $\mathbf{3 8}$ & $\mathbf{4 4 . 1 \%}$ \\
\hline
\end{tabular}

\section{Questionnaire}

For this study, we combined the elements of the CSQ and the UTAUT that were related directly with NPD and $\mathrm{PM}$ to create a CSQ/UTAUT Questionnaire that addressed organization's corporate culture. Portions of the TAM concerning areas pertinent to this organization were also used in the survey of employees and managers.

The CSQ/UTAUT questionnaire was anonymously administered electronically through the organization's intranet. The CSQ/UTAUT questionnaire addressed aspects from the UTAUT questions concerning communications tools used in the organization. These four aspects concerned performance expectancy, effort expectancy, social influence, and facilitating conditions of technology usage as defined by Venkatesh et al., [13] as:

- "Performance expectancy" is the degree to which an individual believes that using the system will help him or her to attain gains in job performance. (p.447)

- "Effort expectancy" is the degree of ease associated with the use of the system. (p. 450)

- "Social influence" is the degree to which an individual perceives that important others believe he or she should use the new system. (p. 451)

- "Facilitating conditions" is the degree to which an individual believes that an organizational and technical infrastructure exists to support use of the system. (p. 453)

The CSQ questions address communication climate, media quality, and horizontal informal communication. These three elements of the CSQ are described thus:

- "Communication climate" examines 1) the extent to which the organization's communication system motivates the workers to meet the organization's goals and 2) whether the workers' attitudes about communication in the organization are healthy.

- "Media quality" questions the satisfaction with communication channels in an organization, such as meeting structures, reports, quality of information, and total amount of communication.

- "Horizontal informal communication" examines the degree to which informal communication networks, include the "grapevine" and "rumor mill," pass accurate and meaningful shared information [17].

Questions over "interdepartmental communications" were added to the survey, concerning the communication flow between groups within an organization [16], [18].

We tailored questions after the numerous examples of CSQ and UTAUT questionnaires found in the academic literature and addressed them to organization's culture.

At the end of the questionnaire an open-end request stated "Please give any comments you would like to add."

\section{Interviews}

In addition to the survey sent to employees, we interviewed six heads of departments (listed in Table 1) and approached them with the same questions. We asked:

- $\quad$ Generally speaking, what makes interdepartmental communications satisfactory or unsatisfactory for your department? Why?

- When dealing with new products specifically, what communication problems do you encounter?

- In the survey, we looked at Syteline, GDS/ECN, Task Manager, and the Intranet as communication tools. What are some ways these tools can be modified to help receive and transmit communications with departments that you interact with?

- $\quad$ Are there other ways that technology might enhance interdepartmental communication during New Product Development?

- How can communication protocols like you described be enforced and maintained?

- Is there anything else you would like to add?

We recorded the interviews and then analyzed the results. The shortest interview was 17:40 minutes - the longest was 37:45 minutes.

\section{STUDY FINDINGS}

The quantitative and qualitative data from the study uncovered four primary areas of concern when examining interdepartmental communications during NPD: lack of central authority, confusion of department roles, the structure of project meetings, and basic communication. (Space limitations prevent a complete description of the survey and interview results, but they are available on request.) 


\section{Lack of central authority}

In the current NPD process, no central authority leads each project. While there are periodic update meetings, each department is concerned with its own duties within the team rather than with the entire process. If a department encounters a problem, no central leader is available to help resolve the problems, inform the other departments, and adjust the project timeline.

In survey comments and interviews with department managers, lack of central authority was a common thread, as exemplified below:

[Problems include] "lack of knowing who is leading the new product development, and who needs to be in the meetings."

"No one really has the ball."

[Project management] "is not an area that we've really put any focus on... Nobody really has that title-Project Manager. Everybody has that hat to put on, but when you don't really know what that means--and nobody is intentionally trying to not do a good job--but when you don't know what you don't know ... project management's expectation is more than just bringing the team together for a monthly meeting."

"There are no weekly project meetings with cross functional teams which leads to unreal expectations from department to department.

"There is no one place to go and find out about those things [a product's progress]. I do not know what you guys are working on, so I cannot prepare my department."

"To me, it's a process breakdown-we don't have a good process."

"Each department is like a silo system, kind-of closed a little bit, and you really don't know what is happening outside"...

"It's difficult to do the project as a committee-I feel you need one person to take the lead-it doesn't need to be a department manager, but someone who can manage and take the lead-be the one point of contact for everybody, and who can keep the project on task."

With each department working independently, concentrating only on its individual contributions, the process lacks cohesiveness and direction. Many small but important pieces of a project's development are not communicated at all, miscommunicated, or communicated too late to keep the project flowing smoothly. Without central coordination and effective TPC, projects run over budget and behind schedule.

\section{Confusion of department roles}

Lack of clearly communicating the roles of various departments within a project also appeared as a common theme in the survey and interview results.
"There needs to be a protocol of who is involved in those product launches and each person knows their role."

"A problem that comes about with emails is that everybody who should be on the email isn't on the email so that people who should be included aren't."

"All the managers need to be informed at a minimum at every milestone, and it will outline what their role is, what's expected of them and what timeline is associated with it."

"If people don't know their roles, it doesn't matter how much you communicate."

When roles are not clear, tasks are often assumed to be "someone else's responsibility" and not completed at all; delays occur. Similarly, duplication of effort occurs when two departments each believe a task belongs to them, creating waste though inadequate communication.

\section{Meetings as communication tools}

Meetings for this organization were seen as a potential means of enhancing communication in NPD and PM, but limitations were also noted in the questionnaire comments and manager interviews:

"There are no weekly project meetings with cross functional teams which leads to unreal expectations from department to department."

"Often new ideas, equipment, etc. are talked about at meetings and are either implemented or put into production without all of the necessary info, such as manuals, decals, and specs."

[There are] "too many cancelled meetings."

"At managers' meetings with department members, take the opportunity to keep the others in the loop about what your department needs and is planning to do.-Make it a habit."

"We have no idea how to communicate with other departments-by email, by design reviews, by status reports-meetings are called without Outlook Meeting invites or checking Outlook for conflicts."

"But if you're meeting on a regular basis and have that champion doing Project Management, then a lot of that [misunderstandings and confusion] can be worked through quicker than trying to work through email."

Omitting key personnel from meetings creates delays and confusion when bringing them up to date with the project progress and/or explaining their duties. Vital input may be lost or overlooked due to a team member's absence, negating the entire planning session. Including unnecessary personnel in meetings wastes their time and creates dissatisfaction within the team. 


\section{Basic communication}

Data from this study indicate that this organization's communication technology tools are at least satisfactory to the majority of the questionnaire respondents (about 4 points on a 7 point scale). However, the results of the questionnaire also indicate that basic TPC between departments has been unsatisfactory. The four items below dealing with TPC between departments during NPD scored low (3.8 or lower on a 7 point scale).

- I receive timely information on how problems with my project are being handled.

- Meetings have meaningful minutes distributed to attendees.

- $\quad$ I receive most information I need for a new task when it is first assigned.

- I receive project news from other departments in a timely manner.

The questionnaire results indicate that project news and problem resolutions at this organization are not being communicated in a timely manner, new information is incomplete, and reports on meetings are either not distributed or not meaningful. No central authority currently exists to determine the appropriate use of these tools or to ensure that updates occur in a timely manner.

Such problems in TPC result not only in delays of the NPD process, but also generate ill-will between team members.

\section{IMPLICATIONS \& RECOMMENDATIONS}

As indicated by these results, management needs to adopt a project management standard and identify and train talented personnel to become Project Managers as central authorities and effective communicators. A Project Manager keeps all departments informed and all product status information available from in a central location. Trained Project Managers adhere to project management standards and are often certified under those standards [19].

Project management standards today differ from company to company, between industries, and between nations. Although many project and process management and methodology systems are available today, such as Six-Sigma, Agile, Lean, Total Quality Management (TQM), ISO 9001, PRojects IN Controlled Environments (PRINCE2), three leaders stand out: A Guide to the Project Management Body of Knowledge (PMBOK) published by the Project Management Institute [20], PRojects IN Controlled Environments 2 (PRINCE2) originally published in 1996 by Britain's HM Cabinet Office and transferred to AXELOS Ltd in 2013 [21], and the International Organization for Standardization (ISO) based in Geneva, Switzerland [22].

Of these three, PMBOK is most widely used in the United States, and its style is adaptable to meet the needs of this corporate culture. PMI's project management style is also flexible enough to incorporate techniques and philosophies of other management systems, such as Lean or TQM [23].

PMI provides various levels of certification to individuals who qualify through rigorous testing and experience [19]. This organization would greatly benefit from adopting standards developed through decades of collaboration with industries and organizations worldwide [20], enhancing PM, NPD, and TPC.

As a world leader in project management and having flexibility to adapt to many situations, PMBOK is a logical choice for this organization. PMI's project management standards, as outlined in PMBOK, directly address the four areas of concern identified in this study.

\section{PM establishes central leadership}

In addition to the basic knowledge and abilities of PM, PMBOK devotes an entire section [14, Appendix X3] to discussing professional leadership skills necessary for a Project Manager.

A Project Manager is the central authority who coordinates all the needs of the project: task needs, team needs, and individual needs [14]. As the central authority, the Project Manager has a vital role in the organization's overall strategy for project success. PMBOK states:

The project manager's role therefore becomes increasingly strategic. However, understanding and applying the knowledge, tools, and techniques that are recognized as good practice are not sufficient for effective project management. In addition to any areaspecific skills and general management proficiencies required for the project, effective project management requires that the project manager possess the following competencies:

- Knowledge-Refers to what the project manager knows about project management.

- $\quad$ Performance-Refers to what the project manager is able to do or accomplish while applying his or her project management knowledge.

- Personal-Refers to how the project manager behaves when performing the project or related activity. Personal effectiveness encompasses attitudes, core personality characteristics, and leadership, which provides the ability to guide the project team while achieving project objectives and balancing the project constraints [14, p. 17].

By adopting PMI's project management standard, this organization would have the central authority with the leadership and the effective TPC it needs for smooth and successful new product development. 


\section{PM defines department roles}

PMBOK sets forth guidelines addressing all role identification issues within the Knowledge Areas. It provides tools for determining stakeholders (Project Initiation Management and Project Stakeholder Management), which roles the various stakeholders perform (Project Human Resources Management), and how and when to communicate with them (Project Communications Management).

The Project Manager uses these tools to set clear and unambiguous roles for the departments involved in NPD. Individual tasks are identified in the early planning phases, discussed among team members, and assigned to the appropriate departments. Questions concerning roles or responsibilities are directed to the Project Manager. When issues arise, as usually happens during NPD, the Project Manager is involved in resolving the issue, resetting the project timeline, and communicating effectively with team members and stakeholders.

\section{PM conducts effective meetings}

Meetings are essential for communicating within a project team and to stakeholders. The tone, format, attendees, and times are set by the Project Manager in the Communication Plan very early in the project's life cycle [14]. Studies have "looked at communication in technical environments and their survey of engineering and construction project teams overwhelmingly concluded that the regularity with which meetings were held impacted how well a team accomplished its goals" [9].

By adopting PMI's project management standard, this organization can assure that all required attendees are notified of meetings and that appropriate minutes of the meetings are recorded. With a standardized format, attendees also know what format to use when presenting their information to the entire team, thus enhancing TPC within an organization.

\section{PM improves interdepartmental TPC}

A Project Manager following PMBOK's guidance will ensure information is presented in a timely and complete manner to all stakeholders who are affected by it. A Project Manager determines the use of communication tools, and establishes periodic updates.

The knowledge area of Project Communications Management addresses the basic TPC issues identified in the questionnaire and expounds on additional topics.

Effective TPC has been repeatedly noted as the most important success factor for effective project management or NPD [5], [6], [7], [9], [10]. PMBOK acknowledged this, stating, "Planning the project communications is important to the ultimate success of any project" [14, p. 290].

In order to effectively disseminate information and drive a project, a Project Manager must be an excellent communicator [6]. PMBOK lists the communication skills common for project management. These communication skills include, but are not limited to:

- $\quad$ Listening actively and effectively;

- Questioning and probing ideas and situations to ensure better understanding;

- Educating to increase team's knowledge so that they can be more effective;

- $\quad$ Fact-finding to identify or confirm information;

- $\quad$ Setting and managing expectations;

- Persuading a person, a team, or an organization to perform an action;

- Motivating to provide encouragement or reassurance;

- Coaching to improve performance and achieve desired results;

- $\quad$ Negotiating to achieve mutually acceptable agreements between parties;

- Resolving conflict to prevent disruptive impacts; and

- $\quad$ Summarizing, recapping, and identifying the next steps [14, p. 288]

Data from this study indicate that this organization's communication technology tools are satisfactory to the majority of the questionnaire respondents. However, PM enhancements for this organization for using technology for communication could encourage periodic Syteline reports, specific locations on the Intranet for status reports, using Task Manager's Timeline feature, and other technology available there.

\section{DISCUSSION}

This study has identified areas where interdepartmental TPC during NPD is seen by employees and managers as being less than optimal. A lack of central authority to coordinate all aspects of projects emerged as the strongest concern. Two managers specifically used the term "Project Manager" in identifying a need for a better process. Project Management Institute's standards as published in PMBOK specifically address this need for central authority.

PMBOK also offers solutions to TPC concerns uncovered in the questionnaire and interviewsappropriately identifying all stakeholders so they are included in relevant emails and meetings, defining department roles, setting protocols on when and how to communicate within the team, and having a central point of contact for all updates and status reports. PMBOK provides guidelines on all of these areas, and this organization (and others) could enhance NPD and TPC by adopting PM best practices.

Adopting a formal process for PM and TPC of NPD in this organization will greatly reduce the ambiguities in both product specifications and the roles assigned to each department, eliminate the uncertainty of the timelines for milestones, and clarify the status of any product's 
development at any time within the NPD process, promising greater efficiency and satisfaction in developing future products.

\section{APPENDIX}

Survey questions used for this research:

1. The computer system is useful in my job.

2. The information in the computer system is complete.

3. The information in the computer system is accurate.

4. I use the computer system frequently.

5. I am confident that I use the computer system correctly.

6. The computer system is easy to use

7. I would recommend this computer system to others.

8. Locating the correct information is easy.

9. I need to use the computer system for my job.

10. Upper management greatly supports using the computer system.

11. Using the computer system is not compulsory in my job, but it is useful.

12. I have the knowledge necessary to use the computer system.

13. The computer system is compatible with other systems I use.

14. Technical support is responsive for the computer system.

15. I have knowledge resources (e.g. books, documents, training) help me learn about computer system.

16. Our internal publications are helpful to employees.

17. Written directives and reports are clear and concise.

18. Communication with employees in other department is clear and easy.

19. I know the proper format to write our organization's reports, minutes, notices, task requests, etc.

20 . I receive timely information on how problems with my project are being handled.

21 . I need to ask a manager to get coworkers to respond to requests.

22. The "grapevine" is active and accurate here.

23. Coworker conflicts are rare

24. People in our organization have good ability as communicators.

25. Attitudes toward communication at our organization are basically healthy.

26. The amount of communication at our organization is about right.

27. Meetings have meaningful minutes distributed to attendees.

28. I receive most information I need for a new task when it is first assigned.

29. Our online information is well maintained and up to date.

30. I receive project news from other departments in a timely manner.

31. I know which departments need the information I have.
33. Other department members are responsive to my needs.

34. Do you have any comments you wish to share?

\section{REFERENCES}

[1] B. Lauren and J. Schreiber, "An integrative literature review of project management in technical and professional communication." Tech. Commun., vol. 65, no. 1, 2018, pp.85106.

[2] J. Meng and B. Berger, "Measuring return on investment (ROI) of organizations' internal communication efforts." $J$. of Commun. Manage., vol. 16, no. 4, 2012, pp.332-354.

[3] M. Christensen, "Communication as a strategic tool in change processes." Int. J. Bus. Commun., vol. 51, no. 4, 2014, pp.359-385.

[4] A. Griffin and J. Hauser, "Patterns of communication among marketing engineering and manufacturing - A comparison between two new product teams." Manage. Science, vol. 38, no. 3, 1992, pp. 360-373.

[5] D. Pons, "Project management for new product development." Project Manage. J., vol. 39, no. 2, 2008, pp.8287.

[6] J. Pinto, Project Management: Achieving Competitive Advantage. Upper Saddle River, NJ: Prentice Hall, 2012.

[7] B. Felekoglu et al., "Interactions in new product development: How the nature of the NPD process influences interaction between teams and management," J. Eng. and Technology Manage., vol. 30, no. 4, 2013, pp. 84-401.

[8] B. Aubert, V. Hooper, and A. Schnepel, "Revisiting the role of communication quality in ERP project success." Amer. J. Business, vol. 28, no. 1, 2013, pp. 64-85.

[9] P.J. Ziek and D. Anderson, Communication, dialogue and project management. Int. J. of Managing Projects in Bus., vol. 8, no. 4,2015 , pp. $788-803$.

[10] F. Ceveone, "Effective communication for project success," OCLC Syst. and Services, vol. 30, no. 2, 2014, pp.7477.

[11] D. Lee, Y. Rhee, and R. Dunham, "The role of organizational and individual characteristics in technology acceptance." Int. J. Human-Comput. Interaction, vol. 25, no. 7, 2009, pp.623-646.

[12] F. J. Rondan-Cataluña, J. Arenas-Gaitán, and P.E. RamírezCorrea, "A comparison of the different versions of popular technology acceptance models: A non-linear perspective." Kybernetes, vol. 44, no. 5, 2015, pp. 788-805.

[13] V. Venkatesh, et al., "User acceptance of information technology: Toward a unified view." MIS Quart., vol. 27, no. 3, 2003, pp. 425-478. 
[14] Project Management Institute, $A$ Guide to the Project Management Body of Knowledge (PMBOK ${ }^{\circledR}$ guide) (5th ed.). Newtown Square, PA: Project Management Institute, 2004.

[15] E. Zafarani, "Project quality management approaches: A comparative evaluation of international standards." Int. Proc. Econ. Develop. and Research, vol. 15, 2011, pp. 37-43.

[16] K. Zwijze-Koning and M. De Jong, "Evaluating the communication satisfaction questionnaire as a communication audit tool." Commun. Manage. Quart., vol. 20, no. 3, 2007, pp. 262-282.

[17] C. W. Downs and M. Hazen, "A factor analytic study of communication satisfaction." J. Business Communication, vol. 14, 1977, pp.63-73.

[18] C. W. Downs and A. D. Adrian, Assessing Organizational Communication. New York, NY; The Guilford Press, 2004.[19] Project Management Institute, "Certification types." [Online]. Available: http://www.pmi.org/certifications.

[20] Project Management Institute, “About standards." [Online]. Available http://www.pmi.org/pmbok-guide-standards/about.

[21] Axelos. "Enhance my skills." [Online]. Available: https://www.axelos.com/enhance-your-skills-with-axelos.
[22] International Standards Organization. "About ISO." [Online]. Available: http://www.iso.org/iso/home/about.

[23] A. Moujib, "Lean project management," in Proc. PMI Global Congr. 2007, EMEA, Budapest, Hungary, Newtown Square, PA: Project Management Institute.

\section{ABOUT THE AUTHORS}

Rosemarie T. Miller is a graduate student at Indiana University-Purdue University in Indianapolis pursuing a Master of Science in Technology, with a Technical Communication focus. She has work as a Technical Communicator for over 30 years and has experience in various fields and industries, including software, military, manufacturing, and medical. With her studies she in expanding into research of communications within corporations, including the role of communications within Project Management, Lean Six Sigma manufacturing, and global issues of technical communication.

Marjorie Rush Hovde, an Associate Professor of Technical Communication at Indiana University-Purdue University Indianapolis, teaches a variety of graduate and undergraduate courses in technical communication. Her research features observational studies of technical communication practices and practitioners in workplaces. 